\title{
Osteossíntese de mandíbula e maxila em equinos adultos: relato de quatro casos
}

\author{
[Mandibular and maxillary osteosynthesis in adult horses: a report of four cases] \\ F.S. Nóbrega ${ }^{1}$, M.P. Ferreira ${ }^{1}$, M.M. Alievi ${ }^{2}$, C.A.C. Beck ${ }^{2}$, P.C. Gonzalez ${ }^{2}$, \\ I.S. Dal-Bó ${ }^{1}$, R. Stédile $e^{3}$ \\ ${ }^{1}$ Faculdade de Medicina Veterinária e Zootecnia - Universidade de São Paulo - São Paulo, SP \\ ${ }^{2}$ Faculdade de Veterinária - Universidade Federal do Rio Grande do Sul - Porto Alegre, RS \\ ${ }^{3}$ Médico veterinário autônomo
}

\begin{abstract}
RESUMO
Fraturas da mandíbula secundárias a trauma externo não são raras em equinos, sendo este o osso mais comumente fraturado quando o trauma é na região da cabeça. Na maioria dos casos, são abertas e com dano aos tecidos moles adjacentes. Como os ossos da cabeça não são submetidos às forças de carga do apoio, a exigência para fixação da fratura é menos desafiadora. $O$ presente trabalho descreve o tratamento cirúrgico de quatro fraturas de mandíbula em equinos, sendo que, em um caso, havia também fratura de maxila. Quatro cavalos adultos com histórico de traumatismo na região da cabeça foram atendidos, avaliados clinicamente, radiografados e, após diagnóstico, submetidos a tratamento cirúrgico. No primeiro caso, o equino apresentava fratura rostral da mandíbula, sendo esta tratada com cerclagens. Além disso, o animal apresentava fratura múltipla de maxila, que foi corrigida com uma cerclagem próxima aos dentes incisivos, uma placa com parafusos e duas hemicerclagens na região entre os dentes incisivos e pré-molares. $\mathrm{O}$ segundo animal apresentava fratura múltipla dos ramos horizontal e vertical direito da mandíbula e foi tratado com uso de cinco placas de reconstrução e parafusos. No terceiro paciente foi diagnosticada fratura simples no ramo horizontal da mandíbula esquerda, que foi estabilizada com uma placa e parafusos. O quarto paciente apresentava fratura rostral de mandíbula, com avulsão de quatro dentes incisivos, sendo realizada a extração dos dentes incisivos e sutura da mucosa labial. Todos os animais obtiveram consolidação das fraturas em diferentes períodos de pósoperatório, o que permitiu melhora na qualidade de vida.
\end{abstract}

Palavras-chave: cavalo, fratura, placa, cerclagem, osso

\begin{abstract}
Secondary mandible fracture due to external trauma is not uncommon in horses, that being the most commonly fractured bone when the injure is on the animal's head. In most cases, the injuries are open and damaging to surrounding soft tissues. As the bones of the head are not subjected to load forces, the support requirements for fracture fixation are less challenging. This paper describes the surgical treatment of four mandible fractures in horses, and, in one case, the animal had also suffered a fractured jaw. Four horses with a history of trauma to the head region have been examined, clinically and radiographically evaluated, and after being diagnosed, each of them was submitted to surgical treatment. In the first case, the horse showed rostral fracture of the jaw, thus being treated with cerclage. Moreover, the animal had multiple jaw fractures that were fixed with a cerclage next to the incisors, with a plate and two screws and cerclage in the region between the incisors and the premolars. The second animal had multiple fractures of the horizontal and vertical branches of the right jaw and was treated with the use of five reconstruction plates and screws. The third patient was diagnosed with a simple horizontal branch fracture of the left mandible that was stabilized with a plate and screws. The fourth patient had a fracture of the rostral mandible with avulsion of four incisors, and received the extraction of incisors and labial mucosa suture. All animals received fracture treatment in different post surgical periods, allowing improved quality of life.
\end{abstract}

Keywords: horse, fracture, plate, cerclage, bone

Recebido em 12 de agosto de 2012

Aceito em 25 de junho de 2013

E-mail: fernandanobrega.vet@gmail.com 


\section{INTRODUÇÃO}

Traumas envolvendo a região da cabeça em equinos não são raros (Ragle, 1993), podendo resultar em fraturas de mandíbula ou maxila que alteram a capacidade de apreensão e trituração dos alimentos, levando à inapetência ou à anorexia (Ragle, 1993; Valadão et al., 1994). A mandíbula é o osso da cabeça mais comumente fraturado nos cavalos, sendo que esta normalmente é aberta (Tremaine, 1998). As lesões podem ser ocasionadas por coices, acidentes com veículos automotivos, pancadas em objetos estáticos durante exercício ou por acidentes que levam à avulsão de dentes incisivos (Denny, 1989; Auer, 2000), e podem ser diagnosticadas por meio de exame radiográfico ou tomografia computadorizada (Kuemmerle et al., 2009). No equino, a mandíbula sofre repetidas forças durante a mastigação, e a fixação de fratura nesse osso tem por objetivo a restauração da oclusão e o retorno à função (Peavey et al., 2003). As principais formas de estabilização são: cerclagens ou hemicerclagens (Henninger e Beard, 1997; Henninger e Beard, 1999), acrílico intraoral, placa e parafusos (Auer, 2000), fixação esquelética externa (Peavey et al., 2003). Segundo Peavey et al. (2003), a utilização de placa DCP de característica compressiva (dynamic compression plate) proporciona maior resistência biomecânica à flexão, quando comparada à placa de acrílico intraoral associada a cerclagens interdentárias ou a fixador esquelético externo com ou sem cerclagens interdentárias. De acordo com Florin et al. (2005), nestes casos também se pode utilizar placa LC-DCP (low contact-dynamic compression plate). $\mathrm{O}$ presente trabalho objetiva descrever o tratamento cirúrgico de quatro fraturas de mandíbula em equinos adultos, sendo uma delas associada à fratura de maxila.

\section{CASUÍSTICA}

Foram atendidos no Hospital de Clínicas Veterinárias da Universidade Federal do Rio Grande do Sul quatro cavalos adultos, um macho e três fêmeas, com histórico de traumatismo na região da cabeça. Após exames clínico e radiográfico, foram identificadas fraturas na mandíbula e na maxila, sendo então os animais encaminhados para tratamento cirúrgico. Estes foram preparados para a cirurgia de forma asséptica, com tricotomia e antissepsia com álcoo-iodo-álcool. Os animais foram submetidos à anestesia geral inalatória. Como medicação pré-anestésica, receberam xilazina (Sedomin, König) - $1 \mathrm{mg} . \mathrm{kg}^{-1} \mathrm{IV}$ - e a anestesia foi induzida com a associação de quetamina (Dopalen, Vetbrands) - 2mg. $\mathrm{kg}^{-1}$ IV - e diazepam (Santista) - 0,05mg. $\mathrm{kg}^{-1} \mathrm{IV}$-, sendo mantidos em plano anestésico com isoflurano (Isoforine, Cristália) em oxigênio a $100 \%$.

Caso 1. Fratura rostral da mandíbula entre os dois dentes incisivos centrais (pinças) provocada por colisão com veículo automotivo. A fratura foi reduzida com duas cerclagens de fio de aço $1,5 \mathrm{~mm}$ (Synthes ${ }^{\circledR}$ ) ao redor dos dentes incisivos mandibulares (Fig. 1A e 1B). Este animal também apresentava fratura múltipla de maxila entre os dentes incisivos centrais e no espaço interdental direito, sendo esta tratada com duas cerclagens $1,5 \mathrm{~mm}$ (Synthes $®$ ) ao redor dos dentes incisivos, uma placa neutra (Baumer $\left.{ }^{\circledR}\right)$ no espaço interalveolar e duas hemicerclagens (interalveolar) $1,5 \mathrm{~mm}$ (Synthes $®$ ) na região entre os dentes incisivos e pré-molares. Havia também extensa lesão no lábio superior (Fig. 1C), que foi suturada com fio de ácido poliglicólico (Vicryl, Ethicon) $\mathrm{n}^{\circ} 2$ em padrão isolado simples (Fig. 1D).

Caso 2. Fratura múltipla dos ramos horizontal (Fig. 2A) e vertical da mandíbula direita provocada por coice. Esta foi tratada com cinco placas de reconstrução (Aesculapß) e parafusos 3,5mm (Fig. 2B). Houve deiscência da sutura após quatro dias da cirurgia, com exposição óssea, sendo esta tratada como ferida aberta. Trinta dias após a cirurgia, foi identificada formação de sequestro ósseo com presença de solução de continuidade no ramo horizontal. Foram removidos duas placas e alguns fragmentos de osso desvitalizado.

Caso 3. Fratura simples unilateral do ramo horizontal da mandíbula esquerda (Fig. 3A), provocada por colisão com veículo automotivo. A fratura foi reduzida com uma placa DCP (Baumer®) e parafusos 3.5mm (Fig. 3B).

Caso 4. Fratura rostral de mandíbula (Fig. 4A), com avulsão de quatro dentes incisivos (duas pinças, canto e médio do lado esquerdo), provocada por aprisionamento dos dentes em uma cerca. Por haver pouca estrutura óssea 
alveolar entre os dentes avulsionados e por ter passado mais de 72 horas após o trauma, com área apresentando grande contaminação, optou-

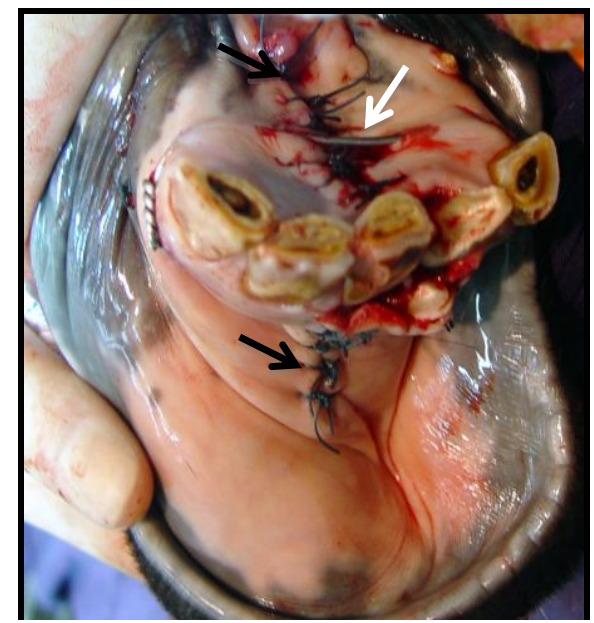

Figura 1A. Fotografia no pós-operatório imediato, onde se identificam o fio de cerclagem (seta branca) utilizado para a estabilização da fratura e a sutura de mucosa sublingual e gengival (seta preta).

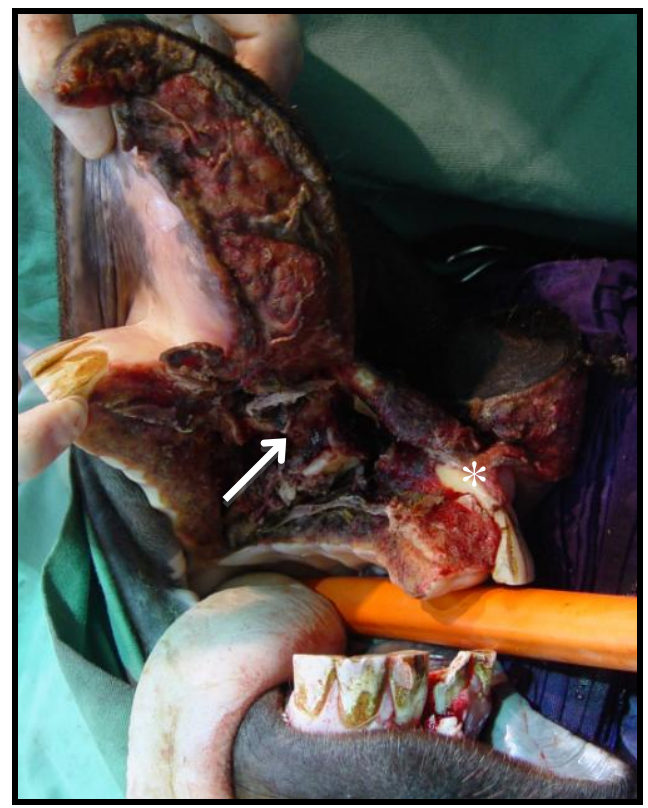

Figura 1C. Fotografia evidenciando extenso dano em tecidos moles, fratura em palato duro (seta branca) e perda de incisivo esquerdo (asterisco).

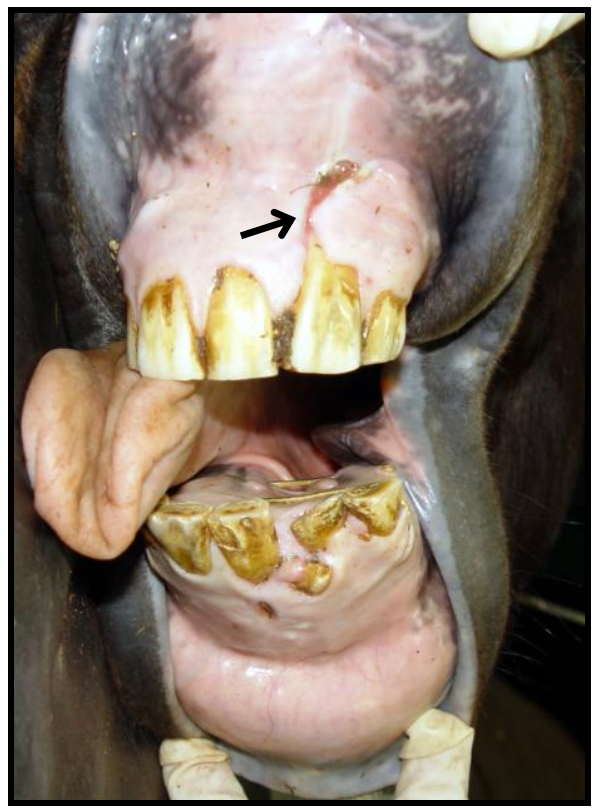

se pela remoção dos quatro incisivos e sutura da mucosa labial com fio de ácido poliglicólico (Vicryl, Ethicon) no 2 (Fig. 4B).

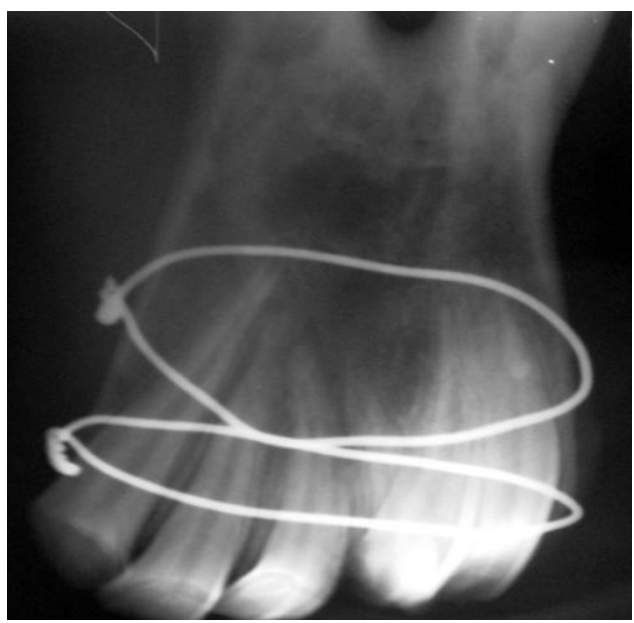

Figura 1B - Imagem radiográfica após redução da fratura com o uso de dois fios de cerclagem.

Figura 1D. Fotografia da boca do equino após 90 de cirurgia onde se notam cicatrização de mucosa (seta) e bom resultado cosmético atingido após a reconstrução. 


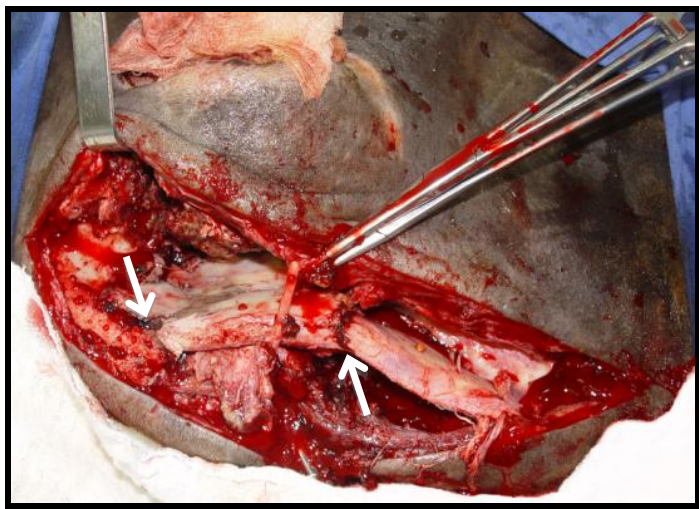

Figura 2A. Fotografia mostrando fratura múltipla (setas) de ramo horizontal da mandíbula direita.

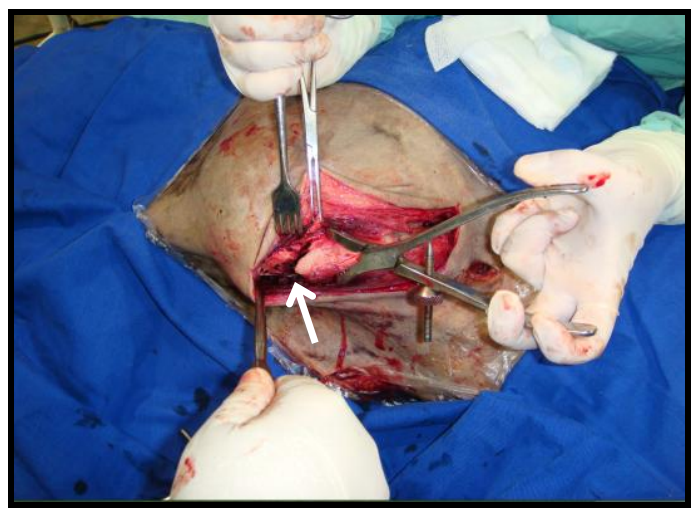

Figura 3A. Fotografia mostrando a identificação do foco da fratura (seta) do ramo horizontal da mandíbula.

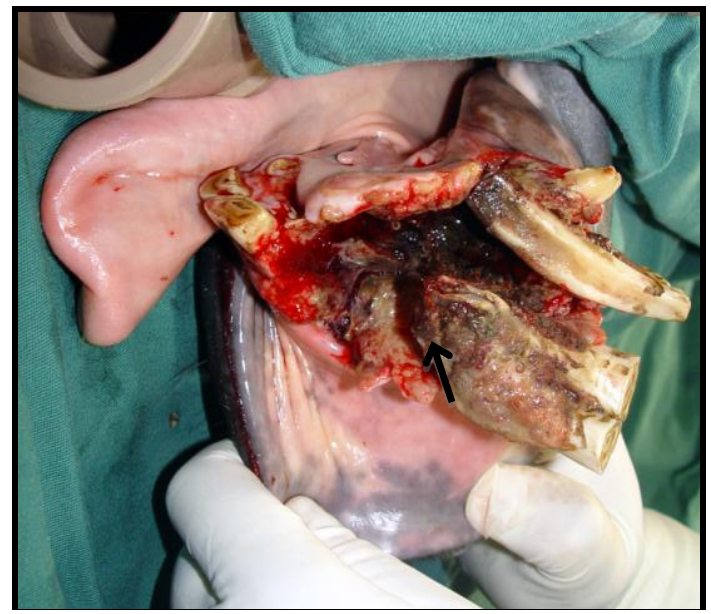

Figura 4A. Fotografia no pré-cirúrgico, onde se observam perda de osso alveolar na região do arco alveolar da mandíbula (seta) e presença de tecido necrótico.

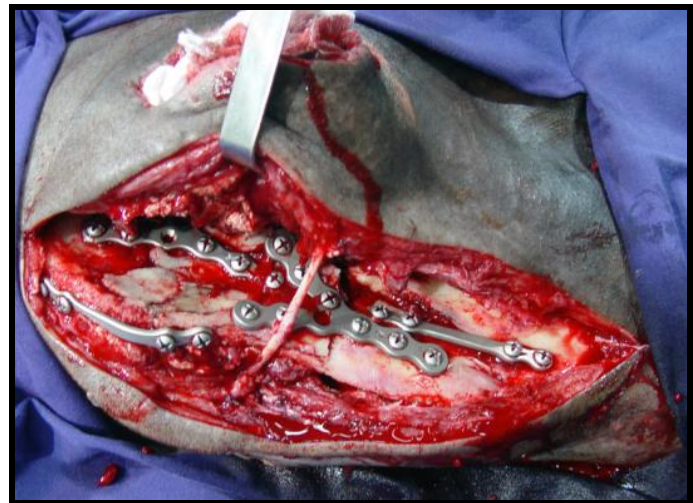

Figura 2B. Fotografia mostrando o resultado final após a redução da fratura com uso de placas de reconstrução e parafusos.

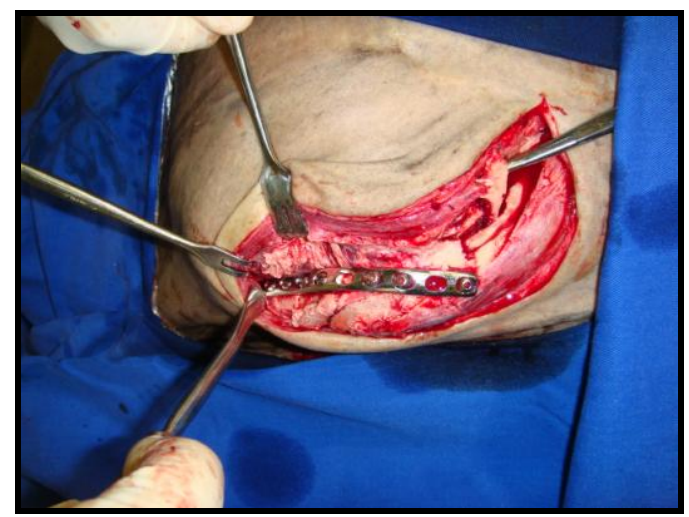

Figura 3B. Fotografia mostrando o aspecto final após redução da fratura de mandíbula com placa DCP 3,5mm e parafusos.

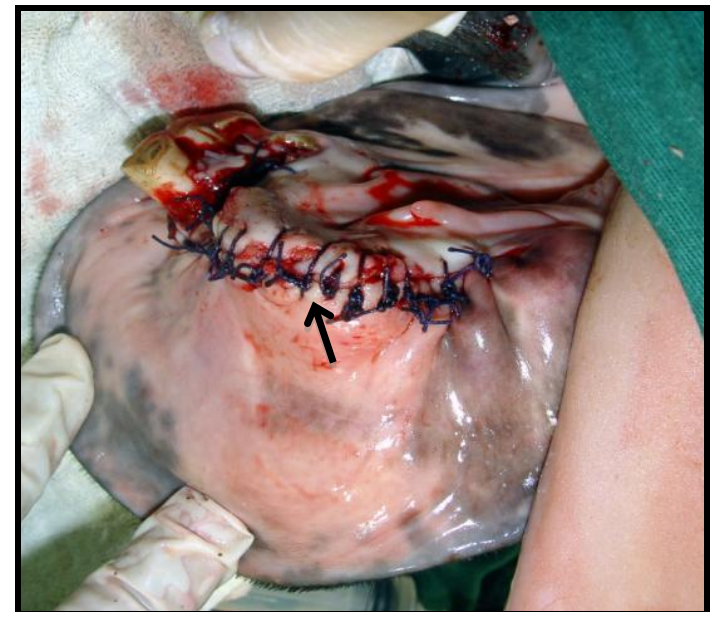

Figura 4B. Fotografia no pós-operatório imediato após extração de quatro dentes incisivos e sutura de mucosa (seta). 
No pós-operatório, os animais receberam analgesia com morfina $\left(0,3 \mathrm{mg} \cdot \mathrm{kg}^{-1}\right.$, tid, 3 dias $)$, fenilbutazona $\left(4,4 \mathrm{mg} \cdot \mathrm{kg}^{-1}\right.$, sid, cinco dias) como anti-inflamatório e os antimicrobianos penicilina $\left(22000\right.$ UI. $\mathrm{Kg}^{-1}$, sid, 10 dias) e gentamicina $\left(6,6 \mathrm{mg} \cdot \mathrm{kg}^{-1}\right.$, sid, sete dias). Os três primeiros animais receberam alimentação pastosa (ração comercial e volumoso diluídos em água) durante quatro semanas após a cirurgia, passando gradativamente para alimentação sólida. Foi realizada higienização oral com água e clorexidina $0,12 \%$ (Periogard, Colgate), três vezes ao dia, nos quatro pacientes. Os resultados estão sistematizados na Tab. 1 .

Tabela 1. Descrição sistematizada dos casos relatados, com apresentação da característica da fratura, do tratamento e do resultado para cada animal

\begin{tabular}{|c|c|c|c|c|c|c|}
\hline Equino & $\begin{array}{l}\text { Tipo de } \\
\text { fratura }\end{array}$ & $\begin{array}{c}\text { Método de } \\
\text { osteossíntese }\end{array}$ & Complicações & Evolução & $\begin{array}{l}\text { Período de } \\
\text { recuperação }\end{array}$ & $\begin{array}{l}\text { Restrições após } \\
\text { recuperação }\end{array}$ \\
\hline Caso 1 & $\begin{array}{c}\text { Fratura } \\
\text { rostral de } \\
\text { mandíbula } \\
\text { Fratura } \\
\text { múltipla } \\
\text { de maxila }\end{array}$ & $\begin{array}{c}\text { Placa e } \\
\text { parafuso + } \\
\text { cerclagem }\end{array}$ & Não & Boa & 90 dias & Não \\
\hline Caso 2 & $\begin{array}{c}\text { Fratura } \\
\text { múltipla } \\
\text { de } \\
\text { mandíbula }\end{array}$ & $\begin{array}{c}\text { Placa de } \\
\text { reconstrução }\end{array}$ & $\begin{array}{l}\text { Sim - } \\
\text { deiscência da } \\
\text { sutura e } \\
\text { exposição dos } \\
\text { implantes }\end{array}$ & $\begin{array}{l}\text { Boa } \\
\text { depois de } \\
\text { retirada } \\
\text { de } \\
\text { implantes }\end{array}$ & 120 dias & Não \\
\hline Caso 3 & $\begin{array}{c}\text { Fratura } \\
\text { simples } \\
\text { de } \\
\text { mandíbula }\end{array}$ & $\begin{array}{l}\text { Placa e } \\
\text { parafuso }\end{array}$ & Não & Boa & 60 dias & Não \\
\hline Caso 4 & $\begin{array}{c}\text { Fratura } \\
\text { rostral de } \\
\text { mandíbula }\end{array}$ & $\begin{array}{l}\text { Extração } \\
\text { dentária e } \\
\text { curetagem } \\
\text { óssea }\end{array}$ & Não & Boa & 30 dias & $\begin{array}{c}\text { Sim - } \\
\text { alimentação } \\
\text { assistida pela } \\
\text { incapacidade de } \\
\text { apreensão }\end{array}$ \\
\hline
\end{tabular}

\section{DISCUSSÃO}

Foi observada fratura de mandíbula nos quatro animais deste relato, sendo esta afecção comum após trauma em cabeça de equinos (Tremaine, 1998). Auer (2000) considerou coices, pancadas em objetos estáticos e avulsão dos dentes incisivos causas frequentes de fratura na mandíbula e na maxila em equinos, sendo causas semelhantes às encontradas nos casos relatados.

A utilização de exame radiográfico foi eficiente na identificação das fraturas rostrais, bem como para o planejamento cirúrgico, no entanto não foi possível visualizar adequadamente as fraturas caudais. Avaliação completa poderia ser feita por meio de tomografia computadorizada (Kuemmerle et al., 2009), porém esse recurso não se encontra disponível para uso em equinos na maioria dos hospitais veterinários.

A aplicação de cerclagens e hemicerclagens é a forma de osteossíntese mais utilizada em fraturas rostrais de mandíbula e maxila (Henninger e Beard 1997; Henninger et al., 1999), apresentando baixo custo e grande versatilidade (Auer, 2000). No primeiro caso do relato, essa técnica de osteossíntese mostrou-se eficiente, tanto para a fratura de mandíbula como para a de maxila, pois permitiu alinhamento adequado dos fragmentos, mantendo-os estáveis até a consolidação óssea. Embora Henninger et al. (1999) afirmem ser comum a falha nesse tipo de fixação nas fraturas de mandíbula e maxila em equinos, no presente relato não foram observadas tais complicações relacionadas com o uso de cerclagens. 
Optou-se pelo uso de placa e parafuso no caso 1 para a fratura de maxila, e nos casos 2 e 3 para as fraturas de mandíbula, pois sua aplicação na região é relativamente simples, como citado por Denny (1989). Esse método de osteossíntese apresenta baixa taxa de complicações (Henninger et al., 1999), o que foi observado nestes casos, com exceção do caso 2, que apresentou falha na estabilização da fratura com necessidade de remoção de duas das cinco placas utilizadas, fato este atribuído à extensa lesão aos tecidos moles, que pode ter predisposto à contaminação e à consequente infecção.

O caso 2, por se tratar de uma fratura múltipla e aberta de mandíbula, apresentava maiores riscos de complicação, como salientado por Kuemmerle et al. (2009), sendo, em casos como esses, segundo Peavey et al. (2003), a utilização de placa e parafuso a técnica que permite maior estabilidade. Um obstáculo para a colocação de placas na mandíbula são as raízes dentárias, fato salientado por Auer (2000). Kuemmerle et al. (2009) concordam que os dentes e as raízes podem limitar o comprimento do parafuso, e para esses casos, Florin et al. (2005) recomendam a utilização de placas LC-DCP, que apresentam maior resistência à movimentação cíclica do osso. Como a fratura do caso 2 envolvia grande parte da mandíbula e principalmente a região do ângulo que apresenta poucas raízes dentárias, foi possível o uso das cinco placas de reconstrução.

A soltura precoce dos parafusos no caso 2 pode ter sido ocasionada pela movimentação interfragmentária durante a mastigação, sendo essa complicação frequente segundo Peavey et al. (2003), que afirmaram ser comum a necessidade de uma segunda intervenção cirúrgica, fato ocorrido no caso 2 do relato para remoção dos implantes soltos e do sequestro ósseo. Após a segunda cirurgia, houve formação de fístula, complicação observada em casos de osteossíntese de mandíbula ou maxila, de acordo com Henninger et al. (1999).

Optou-se pela extração dentária no caso 4 em razão da grande perda óssea alveolar, embora Valadão et al. (1994) e Auer (2000) descrevam a fixação com fio em banda de tensão intraoral como tratamento de fraturas que envolvam essa região. Seguindo a mesma técnica realizada no relato, Alves et al. (2008) removeram quatro dentes incisivos também em razão da perda acentuada de osso alveolar, e o animal apresentou evolução satisfatória.

A escolha pela alimentação pastosa foi uma tentativa de minimizar a movimentação das áreas submetidas à osteossíntese, conduta também adotada por Valadão et al. (1994). Lopes et al. (2001) descreveram a técnica de esofagostomia para alimentação de animais submetidos à osteossíntese, porém, para maior conforto dos animais, optou-se pela dieta líquida com consumo espontâneo. A higienização oral foi fundamental após cada alimentação para reduzir a presença de resíduos alimentares sobre as áreas em cicatrização. Seguiu-se o mesmo protocolo descrito por Reagle (1993), que utilizava enxague bucal com solução de clorexidina $0,12 \%$.

\section{CONCLUSÕES}

Conclui-se que tanto a utilização de cerclagem e hemicerclagens com fio de aço quanto a colocação de placa e parafusos foram efetivas na osteossíntese de mandíbula ou maxila nos equinos deste relato. A remoção de quatro dentes incisivos na fratura rostral de mandíbula também não impediu o animal do caso 4 continuar com apreensão de alimentos pré-cortados. Desta forma, foi possível o retorno funcional e a melhora cosmética dos quatro animais deste relato.

\section{REFERÊNCIAS}

ALVES, G.E.S.; PAGLIOSA, G.M.; OLIVEIRA, H.P. et al. Fraturas odontomaxilares e mandibulares em equídeos tratados por diferentes técnicas de osteossíntese. Arq. Bras. Med. Vet. Zootec., v.60, p.1382-1387, 2008.

AUER, J.A. Mandible, maxilla and skull. In: FACKELMAN, G.E.; AUER, J.A.; NUNAMAKER, D.M. (Eds). Ao principles of equine osteosynthesis, Thieme: New York, 2000. p.35-56.

DENNY, H.R. Fractures of the skull. In: DENNY, H.R. (Ed). Treatment of equine fractures. Wright: London. 2005. p.164-173.

FLORIN, M.; ARZDORF, M.; LINKE, B.; AUER, J.A. Assessment of stiffness and strength of 4 different implants available for equine fracture treatment: a study on a 20 degrees oblique long-bone fracture model using a bone substitute. Vet. Surg., v.34, p.231238, 2005. 
HENNINGER, R.W.; BEARD, W.L. Rostral mandibular and maxillary fractures: repair by interdental wiring. Proc. Am. Ass. Equine Practnrs., v.43, p.136-137, 1997.

HENNINGER, R.W.; BEARD, W.L.; SCHNEIDER, R.K. et al. Fractures of the rostral portion of the mandible and maxilla in horses: 89 cases (1979-1997). J. Am. Vet. Med. Assoc., v.214, p.1648-1652, 1999.

KUEMMERLE, J.M.; KUMMER, M.; AUER, J.A. et al. Locking compression plate osteosynthesis of complicated mandibular fractures in six horses. Vet. Comp. Orthop. Traumatol., v.22, p.54-58, 2009.

LOPES, M.A.F.; POMPERMAYER, L.G.; FELIPE, A.H.B.; ARAUJO, I.C. Nutrição de equinos via esofagostomia. Cienc. Rural., v.31, p.135-139, 2001.
PEAVEY, C.L.; EDWARDS III, R.B.; ESCARCEGA, A.J. et al. Fixation technique influences the monotonic properties of equine mandibular fracture constructs. Vet. Surg., v.32, p.350-358, 2003.

RAGLE, C.A. Head trauma. Vet. Clin. N. Am. Equine Pract. v.9, p.171-183, 1993.

TREMAINE, W.H. Management of equine mandibular injuries. Equine Vet. Educ., v.10, p.146154, 1998.

VALADÃO, C.A.A; MARQUES, J.A.; PADILHA FILHO, J.G. et al. Uso da cerclagem e resina acrílica em fraturas mandibulares dos equídeos. Cienc. Rural., v.24, p.323-327, 1994. 